\title{
COMPARING COMPLEX SYNTAX ACROSS POPULAR CHILDREN'S TELEVISION SHOWS
}

MADISON BURNETT

May 7, 2018 


\section{ABSTRACT:}

Studies indicate that certain television shows, such as Sesame Street and Daniel Tiger's Neighborhood, can positively impact a child's thinking and social skills (Mares and Pan, 2015; Rasmussen, 2016). This study considers syntactic content of popular children's television shows to make predictions of their underlying linguistic value. Therefore, the research questions are: Does Daniel Tiger's Neighborhood have more complex syntactic utterances than Paw Patrol? Does the number of mental state verbs used correlate with complex syntax? Results indicate that Daniel Tiger's Neighborhood consistently uses more complex syntax and mental state verbs than Paw Patrol, and that mental state verb use does significantly correlate with complex syntax. Implications for child language learning are discussed. 


\section{Introduction}

The Nielsen Report (2015) estimated that 97 percent of children between the ages of two and seven watched live television each month. Of the genres watched by that age group, 90 percent of television viewing is children's programming. Professionals agree that media plays a role in shaping a child's cognitive, social, and emotional development because children with typical language and cognitive development have a high capacity to learn from educational television (Evra, 2004; Bonus \& Mares, 2015). Further studies of the linguistic content of children's television programming would benefit parents making an informed decision as to which shows are most beneficial and appropriate for their children to watch.

The television content that children watch has a lasting influence. Studies indicate that certain shows such as Sesame Street and Daniel Tiger's Neighborhood can positively impact a child's thinking and social skills (Mares \& Pan, 2013; Rasmussen, 2016). Empathy, critical thinking, and discussion are emphasized through the frequent use of mental state verbs (e.g., "thinking," "feeling") in these television programs. Child development literature supports the idea that continued exposure to mental state verbs progresses a child's thinking skills and empathy (Evra, 2004). As children master recognizing the emotions, beliefs, and desires in themselves and others, they begin to synthesize information to reflect, hypothesize, and infer (Grazzani \& Ornaghi, 2012). A child's ability to reflect, hypothesize, and infer may prepare children for academic achievement, as well as equip them to emotionally connect with others.

Although academic and social-emotional content of television has received a significant amount of attention in the research literature, less work has directly examined the linguistic content of children's television programming. In fact, the work that has considered the linguistic content of television has primarily focused on vocabulary. Rice and Woodsmall (1990), for example, studied three- and five-year-olds' abilities to learn words from television and found that both groups can learn new vocabulary from television. The ways other domains of language (e.g., morphology and syntax) are represented in children's shows have not been systematically explored.

Current research suggests that shows such as Sesame Street present rare vocabulary words (e.g., words that are not often used in spoken language, or have low frequency) during the television episodes (Larson \& Rahn, 2015). There are specific instructional strategies (e.g. exposure to a word, examples and non-examples) employed to help teach these words to children (Larson \& Rahn, 2015). Children learning new words and concepts require frequent exposure and information within a variety of rich, meaningful contexts. Critical thinking, driven by understanding and use of mental state verbs, plays an integral role in learning. The activities should "promote deep processing of a word's meaning and use" (Larson \& Rahn, 2015).

Complex syntax has been defined in numerous ways, but for the purposes of this paper, the term is defined as the following by Dr. Melanie Schuele (2009) from Vanderbilt University: "[a] complex sentence includes one or more dependent clauses joined to or subsumed within an independent clause, also referred to as the main clause or the matrix clause." Types of complex syntax fall under three categories: conjoined clauses, subordinate clauses, and embedded clauses. Conjoined clauses "[involve] the coordination or linking of two clauses joined by a coordinate conjunction (e.g., and, but, or)" (Schuele, 2009). Subordinate clauses include sentences with subordinating conjunctions (e.g., after, although, if). Embedded clauses are a later developing form of complex syntax in which "one clause is placed or embedded within another clause....and can be finite or nonfinite" (Schuele, 2009). Some embedded clauses contain complement taking verbs in which one verb serves as the object of another verb. Mental state verbs may serve as a complement taking verb in embedded clauses. Reduced infinitive, marked infinitival clause, unmarked infinitival clause, let's clause, wh nonfinite clausal complement, wh finite clausal complement, full propositional clause, and relative clause are types of embedded clauses. A reduced infinitive is the combination of a complement taking verb and infinitival 'to' as one word. In contrast, a complement taking verb with the infinitival 'to' is a marked infinitival clause. Infinitival phras- 
es such as, "she made me bake her a cake," contain an implied subject for the complement taking verb (Schuele, 2009). These are categorized as unmarked infinitival clauses. Clauses with 'let' are categorized as a let's clause, which serves as a special case of a complement taking verb that "does not require production of 'to' in the mainstream English" (Schuele, 2009). Wh nonfinite clausal complements and wh finite clausal complements are structured with complement taking verbs and wh words such as when, what, where. Wh nonfinite clausal complements are marked by an infinitive with 'to', whereas wh finite clausal complements are followed by a finite verb. Full propositional complements are "finite embedded clauses that serve as a complement for cognitive or mental state verbs such as know, wonder, think, guess, pretend, forget, say, mean, tell, remember, wish" (Schuele, 2009). These may be a "finite matrix verb, a nonfinite verb in an infinitival complement, or a nonfinite verb in a participle complement" (Schuele, 2009). Lastly, relative clauses are objects of a verb, oftentimes embedded within a noun phrase.

Children progressively use complex syntax, beginning with reduced infinitival clauses, let's clauses, and simple infinitives (Schuele \& Dykes, 2005). Although children with specific language impairment may have a similar mean length of utterance as typical children, children with specific language impairment are less proficient in complex syntax use. Patterns of omission for 'to' in infinitival clauses, relative markers, and wh pronouns seem to be common for children with specific language impairment. Conversely, their typically developing peers acquire complex syntax without similar grammatical deficiencies (Schuele \& Dykes, 2005).

The purpose of this study is to consider syntactic (i.e., sentence structure) content of popular children's television shows to make predictions of their underlying linguistic value. To date, the only linguistic content that has been evaluated for children's television includes vocabulary knowledge and pragmatic/social knowledge. Current children's television show ratings reveal that Paw Patrol and Daniel Tiger's Neighborhood are extremely popular shows viewed by preschool children (ages two to five).

While considering the academic, social, and linguistic content of children's television shows, it is equally important to evaluate the mission of television producers. Paw Patrol is funded by Nickelodeon, which describes Paw Patrol on their website as "a fun way to learn bravery and heroism, with exciting stories that never get too scary." Paw Patrol partners with the American Society for the Prevention of Cruelty to Animals and intends to teach children lessons about caring for animals. Daniel Tiger's Neighborhood is an off-shoot of Mister Rogers' Neighborhood and is produced by Public Broadcasting Service (PBS). According to their website, this television show "tells its engaging stories about the life of a pre-schooler using musical strategies grounded in Fred Rogers' landmark social-emotional curriculum." The show seeks to teach preschool children "the key social skills for school and for life."

\section{Methods}

First, I acquired 15 most recent episodes of each show, which average 30 minutes each. Next, I transcribed each show orthographically. Orthographic transcription is a transcription method that examines the standard spelling system of the language sample. Then, I edited the orthographic transcriptions and adhered to SALT program conventions (Systematic Analysis of Language Transcripts). SALT is a scholarly resource among researchers for the eliciting, transcribing, and analyzing of language samples.

(see next page for chart) 


\begin{tabular}{|c|c|c|c|c|}
\hline Television Show & Season & Episode Number & Air Date & Length of Episode \\
\hline \multirow[t]{15}{*}{ Daniel Tiger } & 6 & 2 & June 22, 2015 & 26 minutes \\
\hline & & 3 & September 7, 2015 & 26 minutes \\
\hline & & 4 & September 8, 2015 & 26 minutes \\
\hline & & 5 & September 9, 2015 & 26 minutes \\
\hline & & 6 & September 10, 2015 & 26 minutes \\
\hline & & 7 & Februrary 14, 2016 & 26 minutes \\
\hline & & 8 & Februrary 15, 2016 & 26 minutes \\
\hline & & 9 & Februrary 16, 2016 & 26 minutes \\
\hline & & 10 & Februrary 17, 2016 & 26 minutes \\
\hline & 7 & 1 & July 3, 2016 & 26 minutes \\
\hline & & 2 & September 4, 2016 & 26 minutes \\
\hline & & 3 & September 5, 2016 & 26 minutes \\
\hline & & 4 & September 6, 2016 & 26 minutes \\
\hline & & 5 & September 7, 2016 & 26 minutes \\
\hline & & 6 & September 8, 2016 & 26 minutes \\
\hline \multirow[t]{6}{*}{ Paw Patrol } & 5 & 12 & May 25, 2016 & 23 minutes \\
\hline & 5 & 13 & August 21, 2016 & 23 minutes \\
\hline & 6 & 1 & September 15, 2016 & 23 minutes \\
\hline & & 2 & September 15, 2016 & 23 minutes \\
\hline & & 3 & October 9, 2016 & 23 minutes \\
\hline & & 4 & October 17, 2016 & 23 minutes \\
\hline
\end{tabular}




\begin{tabular}{|c|c|c|c|c|}
\hline Television Show & Season & Episode Number & Air Date & Length of Episode \\
\hline \multirow[t]{9}{*}{ Paw Patrol } & 6 & 5 & October 19, 2016 & 23 minutes \\
\hline & & 6 & November 7, 2016 & 23 minutes \\
\hline & & 7 & November 10, 2016 & 23 minutes \\
\hline & & 8 & November 28, 2016 & 23 minutes \\
\hline & & 9 & November 30, 2016 & 23 minutes \\
\hline & & 10 & December 1, 2016 & 23 minutes \\
\hline & & 11 & January 19, 2017 & 23 minutes \\
\hline & & 12 & January 23, 2017 & 23 minutes \\
\hline & & 13 & January 25, 2017 & 23 minutes \\
\hline
\end{tabular}

For the purposes of this study, the transcriptions of episodes were evaluated according to utterances rather than sentences. The completion of sentences and ideas were considered, rather than the conversational turns: in other words, utterances were transcribed as individual sentences/ideas instead of transcribing complete conversational turns as a single utterance. This approach acknowledges "consequential information for the characterization of a complex syntax production" (Schuele, 2009). I chose to code the spoken language with the utterance as the unit of analysis "because spoken utterances do not always conform to sentences" in conforming with the Schuele (2009) protocol. Within the field of speech language pathology, to date, the protocol developed by Dr. Schuele is the only available manual for guidance on coding complexity in spoken utterances that take child language development into account. For example, in Season 7 Episode 5 of Daniel Tiger's Neighborhood, Daniel says, "When you're playing with a friend" then Katerina interjects, "with a friend" as Daniel continues, "and there's something that you need and you can't find it, make it all by yourself." Rather than splitting Daniel's utterances, these are recognized as a single idea. Therefore, the entire section is coded as complex syntax with a mental state verb, subordinate clause, conjunction clause, relative clause, and conjunction clause.

Next, I coded each episode for instances of complex syntax and presence of mental-state (i.e., complement-taking) verbs according to the coding manual developed by Schuele (2009). Common mental state verbs of this study were: think, know, feel, believe, wish, and wonder. In deciding what may or may not be a mental state verb, the word's abstract versus concrete definition played a role in the decision. "Love" as a verb expresses the abstract feeling one has towards another person, place, or thing. Given its abstract nature, "love" was chosen to be a mental-state verb. Although phrases such as "I am glad" express the thoughts and feelings of the character, these were not chosen as mental-state verbs. "Am" serves as the main verb in this phrase whereas "glad" is an adjective. 
Then, I calculated dependent variables using the SALT analysis program as follows: (a) number of complex syntactic utterances per episode, (b) number of each type of complex syntactic utterance (e.g., conjoined clauses, subordinate clauses, and embedded clauses), and (c) number of mental state verbs per episode. Finally, using SPSS statistical software and the guidance of a faculty advisor, I ran a series of analyses to compare the amount of syntax across shows and correlations between mental state verbs and complex syntax. This comparison was done through a t-test.

Other studies of complex syntax and mental state verbs employed this procedure, but never with television. This analysis gave us information about which show is the most linguistically rich relative to syntax and mental-state verbs.

\section{Reliability}

A research assistant collected reliability data from each television show from one third of the episodes. The research assistant was trained by the second author to transcribe and code for instances and types of complex syntax. Reliability was calculated by doing a code-by-code agreement. All reliability codes remained above 80 percent. To see individual code numbers, look at table below. Individual Code Reliability for Paw Patrol and Daniel Tiger represented as percent agreement:

\begin{tabular}{|ccc|}
\hline Complex Syntax Codes & Daniel Tiger & Paw Patrol \\
\hline CS & 87.29 & 87.35 \\
CC & 82.81 & 83.19 \\
SC & 80.01 & 80.00 \\
CAT & 100 & 100 \\
SI & 91.57 & 96.57 \\
UIC & 82.36 & 81.17 \\
LC & 85.33 & 82.35 \\
WNFC & 100 & 88.82 \\
WFC & 80.74 & 82.85 \\
FPC & 86.25 & 80.64 \\
RC & 85.06 & 89.34 \\
MENTAL-STATE VERBS & 89.93 & \\
\hline & & \\
\hline
\end{tabular}


Reliability coders were trained according to training protocol established by Dr. Lund. Coders met with Dr. Lund to discuss the purpose of training and receive training files. The coders were either assigned to undergo orthographic transcription training or complex syntax training.

Orthographic transcription training entailed reviewing the manual and transcribing five minutes of a video clip while adhering to set conventions. The transcriptions were reviewed and corrected by Dr. Lund. Once the coders demonstrated task mastery, they were approved to begin orthographic transcription for the study.

Coders were instructed to read the manual used for this study, then practice coding the presence of complex syntax and complex syntax types in an old episode of Daniel Tiger's Neighborhood and Paw Patrol. Preliminary coding attempts were reviewed and corrected, then individual meetings were scheduled with the two complex syntax reliability coders. The coders continued coding segments as prescribed by Dr. Lund until they exhibited competence. Once the coders demonstrated task mastery, they were approved to begin complex syntax coding for the study.

\section{Results}

The first research question addressed whether Daniel Tiger's Neighborhood has more complex syntactic utterances than Paw Patrol. To answer the question, Dr. Lund and I calculated dependent variables using the SALT analysis program as follows: (a) number of complex syntactic utterances per episode, (b) number of each type of complex syntactic utterance (e.g., conjoined clauses, subordinate clauses, and embedded clauses), and (c) number of mental state verbs per episode. An independent samples t-test compared the amount and types of complex syntax in Daniel Tiger's Neighborhood and Paw Patrol. There was a significant difference in the scores for complex syntax in Daniel Tiger's Neighborhood ( $M=125.27, S D=18.90)$ and complex syntax in Paw Patrol $(M=84.67$, $\mathrm{SD}=11.09)$ conditions; $t(28)=-7.18, p<0.01$.

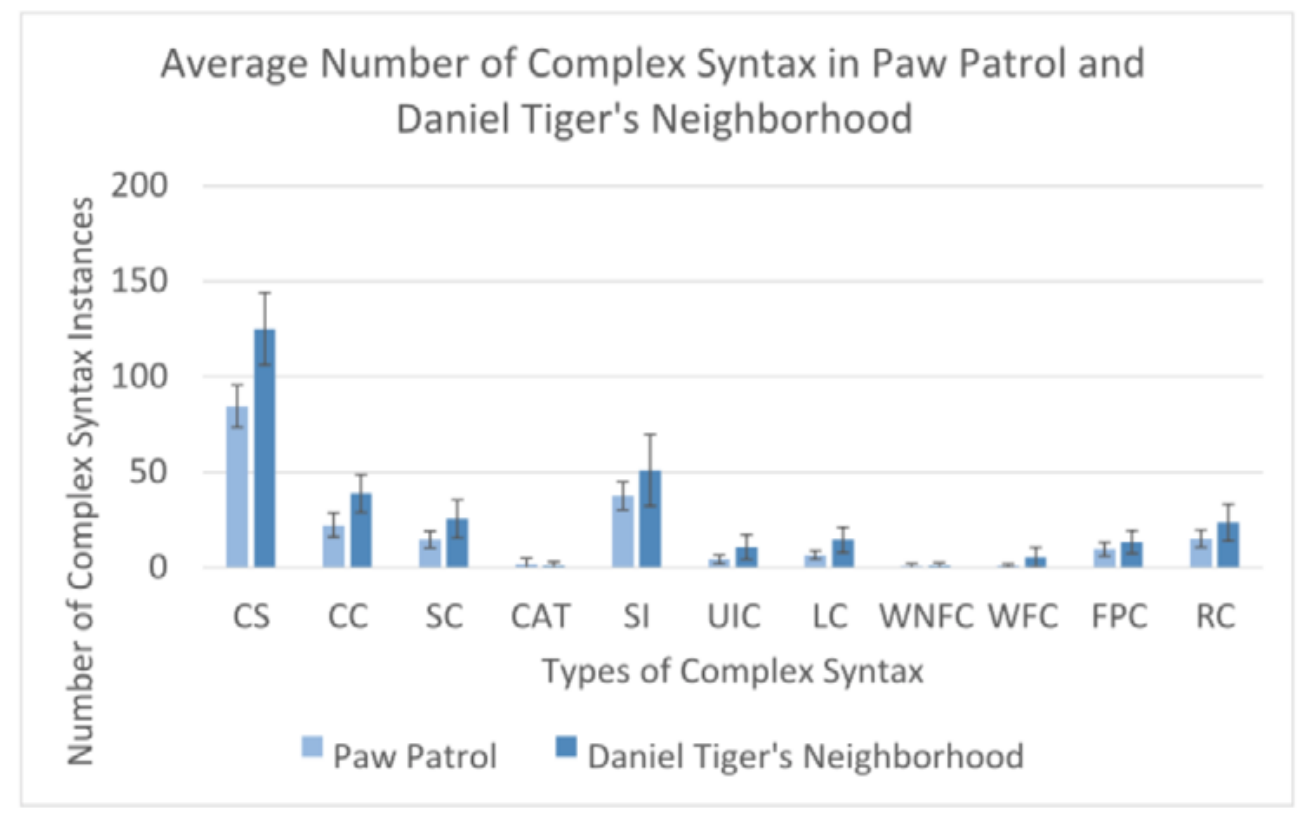




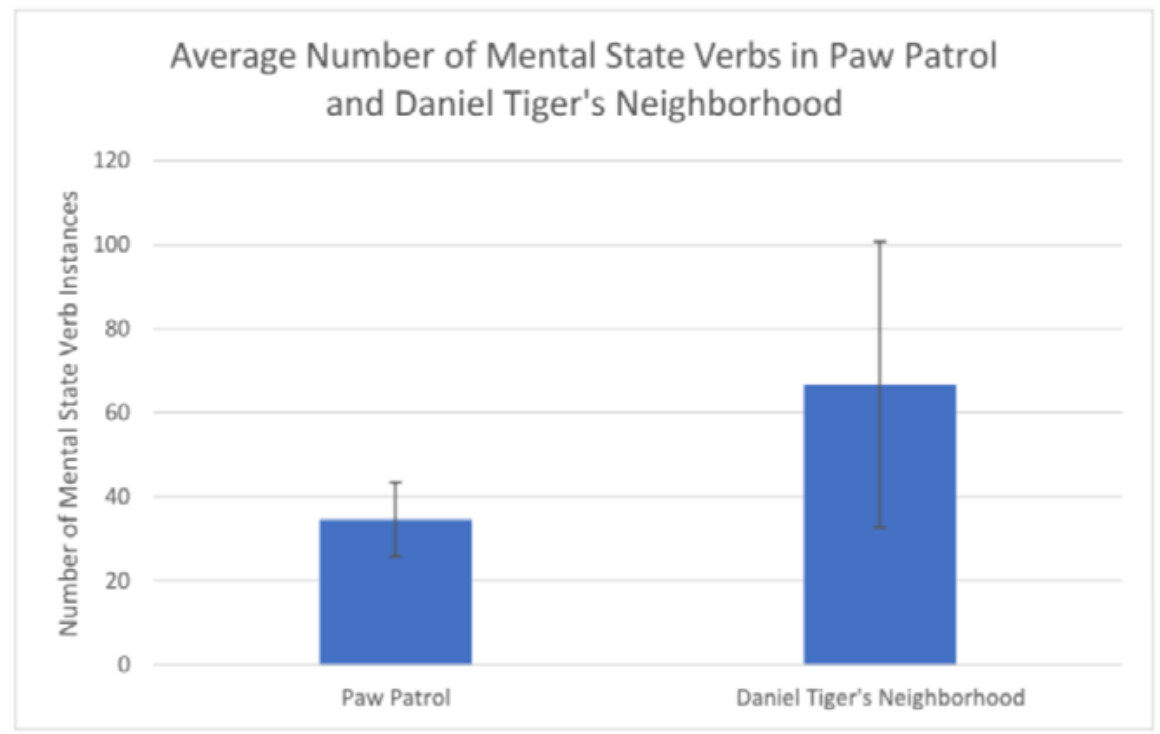

There were significant differences across several types of complex syntax, specifically in conjoined clauses, subordinate clauses, marked infinitival clauses, unmarked infinitival clauses, let's clauses, wh finite clauses, relative clauses, and nominal relative clauses. There was a significant difference in the scores for conjoined clauses in Daniel Tiger's Neighborhood ( $\mathrm{M}=38.80, \mathrm{SD}=9.89)$ and conjoined clauses in Paw Patrol $(\mathrm{M}=22.33 \mathrm{SD}=6.34)$ conditions; $t(28)=-5.43, p=0.000$. There was a significant difference in the scores for subordinate clauses in Daniel Tiger's Neighborhood $(M=25.60, S D=10.01)$ and subordinate clauses in Paw Patrol $(M=14.80, S D=4.38)$ conditions; $t(28)$ $=-3.83, p=0.001$. There was a significant difference in the scores for marked infinitival clauses in Daniel Tiger's Neighborhood ( $M=51.07, S D=18.69)$ and marked infinitival clauses in Paw Patrol $(M=37.67, S D=7.32)$ conditions; $t(28)=-2.59, p=0.015$. There was a significant difference in the scores for unmarked infinitival clauses in Daniel Tiger's Neighborhood ( $M=10.73, S D=6.49)$ and unmarked infinitival clauses in Paw Patrol $(M=4.47, S D=2.23)$ conditions; $t(28)=-3.54, p=0.001$. There was a significant difference in the scores for let's clauses in Daniel Tiger's Neighborhood ( $M=14.60, S D=6.62)$ and let's clauses in Paw Patrol $(M=6.67, S D=2.16)$ conditions; $t(28)=-4.41, p=$ 0.000. There was a significant difference in the scores for wh finite clauses in Daniel Tiger's Neighborhood ( $M=5.47$, $S D=5.19)$ and wh finite clauses in Paw Patrol $(M=1.13, S D=0.92)$ conditions; $t(28)=-3.18, p=0.004$. There was a sig nificant difference in the scores for relative clauses in Daniel Tiger's Neighborhood (M=23.60, SD=9.55) and relative clauses in Paw Patrol $(M=15.26, S D=4.49)$ conditions; $t(28)=-3.06, p=0.005$. There was a significant difference in the scores for mental state verbs in Daniel Tiger's Neighborhood (M=66.73, SD=33.97) and mental state verbs in Paw Patrol $(M=34.60, S D=8.78)$ conditions; $t(28)=-3.55, p=0.001$. These results suggest that Daniel Tiger's Neighborhood has significantly more complex syntax than Paw Patrol.

The second research question addressed the correlation between mental state verbs used and the amount of complex syntax present. Using SPSS statistical software and guidance of faculty advisor Dr. Lund, I ran a series of analyses to compare the amount of syntax across shows and correlations between mental state verbs and complex syntax. A Pearson product-moment correlation coefficient assessed the relation between the amount of mental state verbs and complex syntax for each show. 
There was a significant correlation between mental state verbs and the amount of complex syntax present across both shows $[r=0.64, n=30, p=.00]$. Overall, there was a moderate, positive correlation between mental state verb use and amount of complex syntax. Increases in mental state verb use were correlated with increases in complex syntax use. By type, mental state verbs were significantly correlated with infinitival clauses $[r=0.53, n=30, p=0.000]$, wh finite clauses $[r=0.78, n=30, p=0.000]$, and full propositional complements $[r=0.69, n=30, p=0.000]$.

In amount of complex syntax between Daniel Tiger's Neighborhood $(n=15)$ and Paw Patrol $(n=15)$, there was a statistically significant difference between the two television shows, Daniel Tiger's Neighborhood ( $M=125.27$, $S D=18.89)$ and Paw Patrol $(M=84.67, S D=11.09), t(28)=-7.18, p=0.000$. Therefore, we reject the null hypothesis that there is no difference in reading scores between teaching teams.

\section{Discussion}

Digital media, including television, has become increasingly popular in American households with young children. American children tend to watch two hours of television each day, and some children watch more than recommended (Cespedes et al., 2014). Although excessive media consumption may be detrimental to development (Lin et al., 2014), studies show there are certain television shows that can improve a child's thinking and social skills. Given the prevalence of media consumption, it seems fitting to consider how parents, educators, and professionals can leverage television to promote linguistic development in children. Parents should make an informed decision as to which children's television shows and content their children should watch. Current research suggests that children begin to use complex syntax, utterances with more than one verb phrase, in preschool (Barako Ardnt \& Schuele, 2013). Since children learn simple and complex sentences simultaneously, preschool age children have a critical period in which they should receive increased exposure to complex syntax (Barkao Ardnt \& Schuele, 2013). Increasing proficiency of complex syntax and mental state verb use predicts later academic success and prepares children to engage in academic discourse at a higher level (Scott \& Windsor, 2000; Barkao Ardnt \& Schuele, 2013). While we know that certain educational shows such as Sesame Street and Daniel Tiger's Neighborhood have been proven to aid in a child's social and emotional development, this study evaluates the linguistic content that has been under-explored (Mares and Pan, 2015; Rasmussen, 2016).

The results of this study show us that linguistic content does vary across different children's television shows. For example, Daniel Tiger's Neighborhood has significantly more complex syntax and use of mental-state verbs than Paw Patrol. A significant difference was found in complex syntax, conjoined clauses, subordinate clauses, marked infinitival clauses, unmarked infinitival clauses, wh finite clausal complements, and relative clauses. Daniel Tiger's Neighborhood incorporated an average of 125.27 instances of complex syntax per episode whereas Paw Patrol used an average of 84.66. The proportion of complex syntax is another area to consider in this study. To put these numbers into a wider context, about 30 percent of a teacher's utterances are laden with complex syntax over a twohour period. Within the 23 and 26 minutes episodes from Daniel Tiger's Neighborhood and Paw Patrol, about 40 percent of the spoken utterances were complex. The density of complex syntax in educational television is a compelling feature of this study. Although comparatively the proportions are similar, these television shows present more complex syntax in a shorter amount of time. Plante (2013) reported that high-variability conditions elicited the greatest increase of morpheme use in children in comparison to low-variability conditions. Repeated exposure to complex syntax could help with learning as more instances and variability of complex syntax occur. 
Daniel Tiger's Neighborhood, overall, presents more complex syntax during episodes than Paw Patrol. During coding, we noted that complex syntax types that can include mental state verbs (full propositional clauses, wh nonfinite clausal complements, wh finite clausal complements) tended to actually include those verbs, rather than just including a complement-taking verb, like "said," in Daniel Tiger's Neighborhood. In contrast, Paw Patrol frequently used complement-taking verbs such as "said" or "tell" rather than mental-state verbs. A lexicon rich with emotional and mental state words serves as the foundation to social understanding (Taumoepeau \& Ruffman, 2008). It underpins one's ability to express themselves in a sophisticated manner, build empathy, and succeed academically. Expanding children's comprehension of metacognitive vocabulary can lead to improved ability to "recognize the internal states of self and others" (Grazzani \& Orgnaghi, 2012). As children are able to comprehend and articulate the desires, beliefs, and emotions of self and others, they will integrate this information across other domains of their social, emotional, and cognitive identities (Grazzani \& Orgnaghi, 2012). Increased exposure to mental-state verbs can increase a child's use and understanding. It may be argued that even though Paw Patrol had instances of complex syntax, the content of these complex sentences differs greatly from Daniel Tiger's Neighborhood. Since the amount of complex syntax used positively correlates with mental-state verbs, we see significantly more mental-state verbs in Daniel Tiger's Neighborhood than Paw Patrol.

Although this is a preliminary study to understand the underlying linguistic content of television shows, there are some limitations. Our sample size of complex syntax analysis evaluates only fifteen episodes within each television show. A comprehensive linguistic analysis of both Daniel Tiger's Neighborhood and Paw Patrol would yield more precise complex syntax data. Furthermore, the content of the shows may have evolved throughout the seasons, which could alter complex syntax output within the television shows. Although literature suggests children may acquire more complex syntax by watching television with high amounts of complex syntax, there is no concrete evidence of its benefit. Mares and Pan (2013) compiled studies with more than 10,000 children from 15 countries to gain better insight of learning from Sesame Street. Participants who watched Sesame Street consistently showed better cognitive outcomes, deeper understanding of the world, and social attitudes (Mares \& Pan, 2013). However, many factors impact the generalization of educational content, including: personal perceptions, motivations, and characteristics on the viewing context (Evra, 2004). Strategies implemented to convey information must be robust with meaningful opportunities to learn and age appropriate (Larson \& Rahn, 2015). Furthermore, the information must be presented in multiple conditions and resonate with the viewer (Bonus \& Mares, 2015). In light of these nuances to language learning, children with typical language or with language impairments may be overstimulated or confused from overuse of complex syntax. Increased complex syntax exposure may or may not be beneficial to children.

To advance our knowledge base of complex syntax in children's television and its benefit, some potential future directions of this study may include a broader analysis of the television shows or an intervention study. Rather than evaluating fifteen episodes, it may be valuable to examine over thirty episodes across multiple seasons. Popular television shows other than Daniel Tiger's Neighborhood and Paw Patrol may be evaluated and compared as well. Conducting a full analysis of various children's television shows may help us understand how Daniel Tiger's Neighborhood and Paw Patrol's linguistic richness compares with others. The parent-child interaction plays a critical role in a child's social, emotional, and linguistic development (Taumoepeau \& Ruffman, 2008). Ongoing parent-child dialogue about Daniel Tiger's Neighborhood shows resulted in positive increases of empathy, self-efficacy, and emotion recognition (Rasmussen, 2016). Information about Daniel Tiger's Neighborhood's effect on complex syntax use in children could lead to better understanding of educational television's impact on children and potential implementations in clinical therapy. 


\section{References}

(2017). About Paw Patrol: Paw Patrol Values. Retrieved from http://www.pawpatrol.com/about

(2018). Daniel Tiger's Neighborhood: About the Program. Retrieved from www.pbs.org/parents/daniel/about/

Barako Arndt, K., \& Schuele, M. (2013). Multiclausal utterances aren't just for big kids: a framework for analysis of complex syntax production in spoken language of preschool-and early school-age children. Top Lang Disorders, 33(2), 125-139.

Bonus, J. A., \& Mares, M. (2015). Learned and remembered but rejected: preschoolers' reality judgments and transfer from Sesame Street. Communication Research, 1-26. Sage Publishers. Web.

Cespedes, E.M., Gillman, M.W., Kleinman, K., Rifas-Shiman, S.L., Redline, S., \& Taveras,E.M. (2014). Television viewing, bedroom television, and sleep duration from infancy to mid-childhood. Pediatrics, 133(5), e1163-e1171.

Evra, J. (2004). Television and Child Development. 3rd ed. Mahwah, NJ: Lawrence Erlbaum Associates.

Neilsen Report. (2015). Kids' Audience Behavior Across Platforms. [Data file]. Retrieved from www.nielsen.com/ us/en/insights/reports/2015/kids-audience-behavior-across-platforms.html

Lin, L. Y., Cherng, R. J., Chen, Y. J., Chen, Y. J., \& Yang, H. M. (2015). Effects of television exposure on developmental skills among young children. Infant Behavior and Development, 38, 20-26.

Mares, M.L., \& Pan, Z. (2013). Effects of Sesame Street: A meta-analysis of children's learning in 15 countries. Journal of Applied Developmental Psychology, 34(3), 140-151.

Plante, E., Ogilvie, T., R., Aguilar, J.M., Dailey, N.S., Meyers, C.,...Burton, R. (2014).Variability in the language input to children enhances learning in a treatment context. American Journal of Speech-Language Pathology / American Speech-Language-Hearing Association, 23(4), 530.

Rasmussen, E. E., Shafter, A., Colwell, M. J., White, S., Punyanunt-Carter, N., Densley, R.L., \& Wright, H. (2016). Rela tion between active mediation, exposure to Daniel Tiger's Neighborhood, and US preschoolers' social and emotional development. Journal of Children and Media, 10(4), 443-461.

Rice, M., Hutson, A., Truglio, R., \& Wright, J. (1990). Words from "Sesame Street": learning vocabulary while viewing. Developmental Psychology, 26(3), 421-428.

Schuele, M. \& Dykes. J. (2005). Complex syntax acquisition: A longitudinal case study of a child with specific language impairment. Clinical Linguistics \& Phonetics, 19(4), 295-318.

Schuele, M. (2009). Complex Syntax Coding Manual. Unpublished but available through request from the author.

Taumoepeau, M., \& Ruffman, T. (2008). Stepping stones to others' minds: maternal talk relates to child mental state language and emotion understanding at 15, 24, and 33 months. Child Development, 79(2), 284-302. 